\title{
A Unique Anatomical Variant of the Levator Scapulae Muscle: A Case Report
}

\author{
Adegbenro Omotuyi John Fakoya ${ }^{1 *}$, Samantha Michelle De Filippis ${ }^{2}$, Aaron D'Souza ${ }^{2}$, Gabriela Arizmendi-Vélez ${ }^{2}$

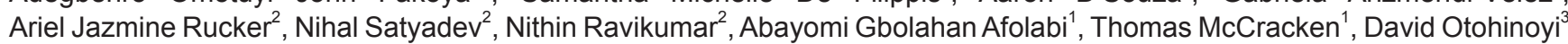 \\ ${ }^{1}$ Department of Anatomy, University of Medicine and Health Sciences, Basseterre, St. Kitts and Nevis; ${ }^{2}$ Medical Student, \\ University of Medicine and Health Sciences, Basseterre, St. Kitts and Nevis; ${ }^{3}$ Department of Research, All Saints University, \\ College of Medicine, Saint Vincent and Grenadines
}

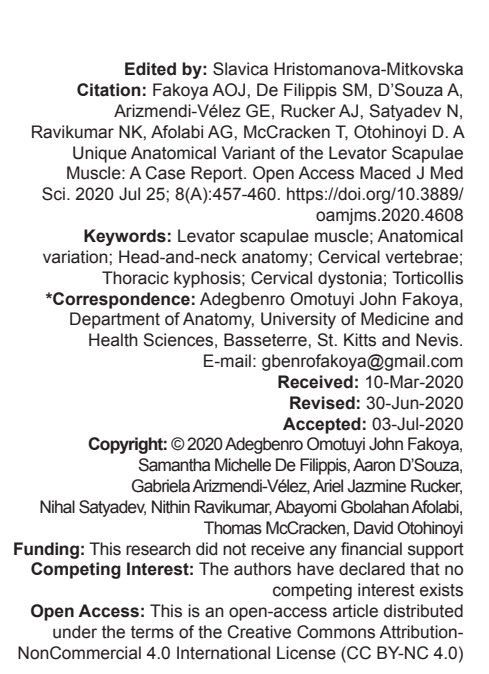

Introduction

Anatomical knowledge of the localization of muscles and their possible variations could be helpful in preventing misrecognition of adjacent structures. Such distinctions could be especially important in surgeries [1]. The levator scapulae muscle (LSM), normally originating from the transverse process $\mathrm{C}-1$ to C-4 and inserting on the superomedial border of the scapula, aids in the process of elevating the shoulder girdle and downwardly rotating the scapula [2]. Since variations in back muscles can often be asymptomatic, they are frequently found in cadaveric dissections [1]. Several case reports have recorded variations in the LSM with as many as 6 muscle slips at the proximal attachment [1], [3], [4]. One study reported accessory attachments to the LSM unilaterally to the serratus anterior (SA) muscle, serratus posterior superior (SPS) muscle, or to either of the first two ribs. Other subjects from the same study demonstrated bilateral accessory attachments to SA with one having had bilateral accessory attachments to SPS and a unilateral accessory attachment to SA. One subject had bilateral attachments to both SPS and SA [1].

In 2016, the researchers Chotai et al. reported that they encountered an additional slip of the LSM originating from the left mastoid process of a cadaveric dissection [4]. It was also documented that in a 71-yearold Caucasian female, her LSM gave rise to an accessory head that inserted, by way of aponeurotic band, into the ligamentum nuchae, the tendon of the rhomboideus major, and the superior aspect of the SPS muscle [5]. In the current case report, we describe an 88-year-old male cadaver with a unique LSM variation, a second belly attaching to the mastoid process which has not been previously reported in the reviewed literature.

\section{Case Report}

On routine dissection at the University of Medicine and Health Sciences Anatomy Lab of an 
88-year-old male cadaver that expired from myocardial infarction, the LSM variant was discovered during the exploration of the left upper back and neck. This muscle can be found in the floor of the posterior cervical triangle. To locate this muscle, the trapezius was dissected from its origin and reflected superiorly and laterally. Immediately deep to that, the splenius capitis was also reflected superiorly, thus exposing the left LSM.

On the left side of the cadaver, it was noticed that the LSM displayed a bifurcation of the belly into two separate bellies (Figure 1). This abnormality was noted unilaterally as the right-sided LSM appeared normal. This LSM variant inserted normally, into the superomedial border of the scapula, then split into two bellies (Figure 1). The insertion of the first belly (labeled right) was normal (Figure 2), as it was inserted into the transverse processes of the cervical vertebrae C1-C4 (Figure 2). The second belly (labeled left) inserted onto the mastoid process (Figure 2). Regarding its innervation and blood supply, the variant LSM had an unremarkable supply. It was innervated by the dorsal scapular nerve and received blood from the dorsal scapular artery; a branch of the transverse cervical artery.

On initial inspection of the cadaver, it was noticed that the cadaver displayed thoracic kyphosis, a clinically relevant finding potentially related to the anomaly seen in the LSM [3] (Figure 3).

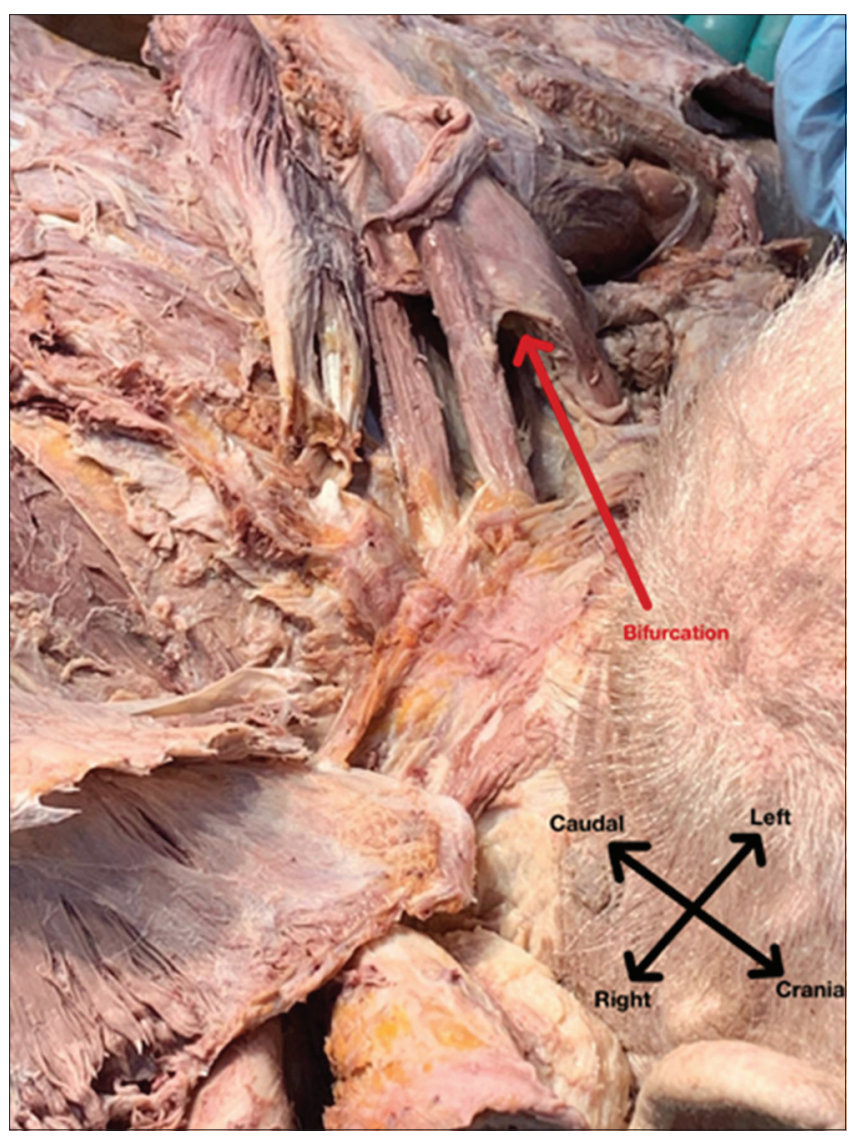

Figure 1: An 88-year-old man with a bifurcated left levator scapulae muscle

\section{Discussion}

Although seemingly uncommon, variations of the LSM have been previously reported in various cases. For example, Loukas et al. found an accessory head attaching to the ligamentum nuchae, a tendon of the rhomboid major and the SPS [5]. A study by Chotai et al. found a portion of the LSM originating superiorly from the mastoid process [4]. Findings listed in Bergman's comprehensive encyclopedia of human anatomic variation note slips of an inferior portion of the muscle attaching to different sites of the scapula [6]. Another study by Lima et al. found that the muscle had split inferiorly, with a medial band attaching to the anterior aspect of the rhomboid major muscle, and the lateral band attaching to the superior angle of the scapula [7].

It is possible that this variation is due to changes within embryological mechanisms specifically relating to the somite forming unit during paraxial mesoderm differentiation. Changes in WNT and fibroblast growth factor signaling gradients can lead to variations in cell movements during gastrulation [8]. The muscle develops from the paraxial mesoderm from the somite which results in the development of the rhomboid major and rhomboid minor [9]. It has also been determined that the SPS and the SA share somitic origin in which an magnetic resonance imaging study found $43 \%$ of their subjects to have attachments to these two areas [1]. The thoracic myotome origin of the LSM and back muscles are known to share innervation from the dorsal scapular nerve [1], [10]. Despite the double belly variation of the LSM, we found the innervation to be from the dorsal scapular nerve with vascular supply from the dorsal scapular artery. However, a study conducted in 1997 reported that the dorsal scapular nerve only innervated the LSM $30 \%$ of the time, with most innervations coming from cervical plexus origins (C3-4) [9]. Alternatively, a 2016 cadaveric study reported that the LSM was innervated solely by the

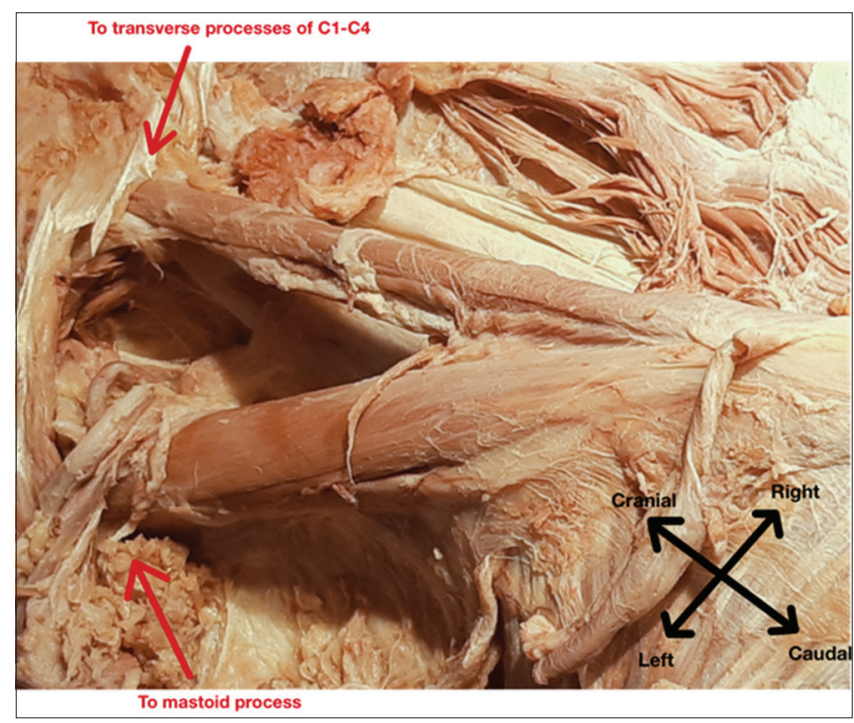

Figure 2: Insertion points of the levator scapulae muscle (LSM) of an 88-year-old man with a bifurcated LSM 
dorsal scapular nerve in $48 \%$ of cases and that the LSM and rhomboids were both innervated by the same dorsal scapular nerve in $52 \%$ of samples [9].

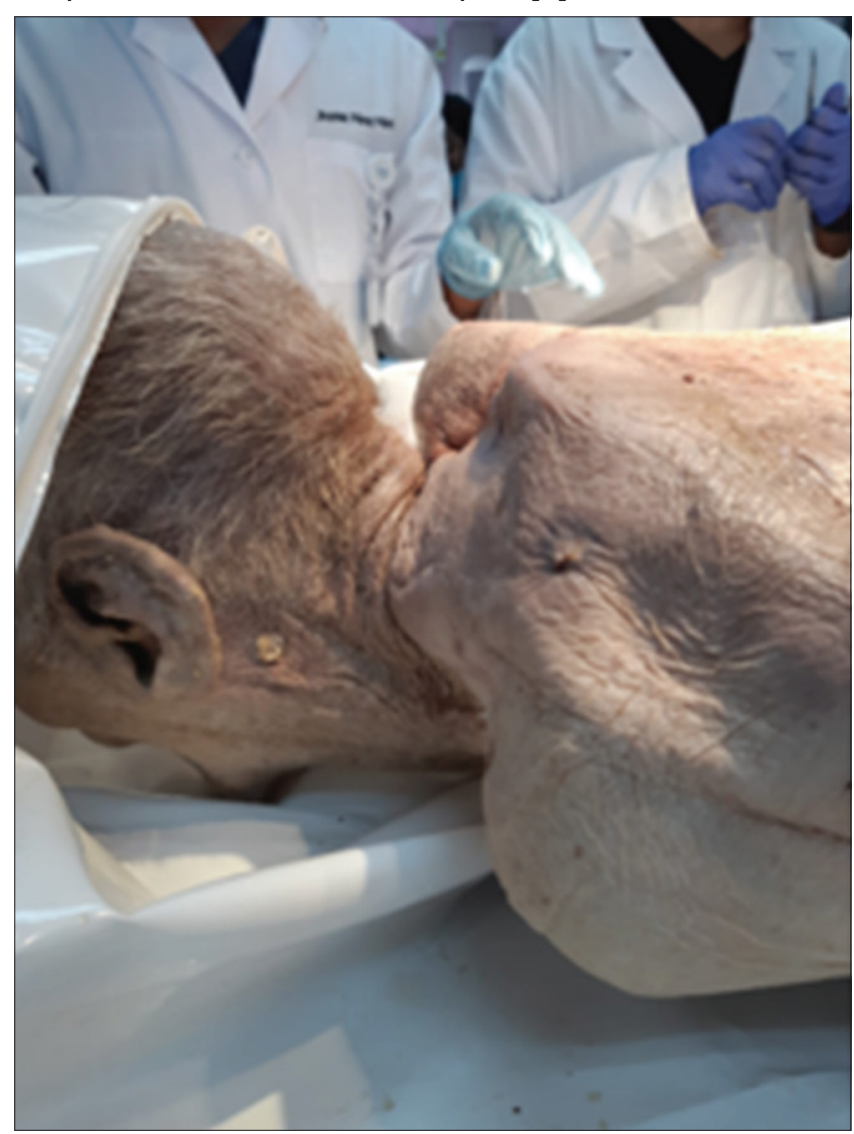

Figure 3: Thoracic kyphosis seen in the 88-year-old man being referenced in this case study

Our cadaver presented with two separate bellies of the LSM unilaterally (Figure 1). Positioned on the floor of the posterior triangle of the neck, the LSM connects the cervical vertebral column to the upper limbs. Superiorly, it originates on the transverse processes of the cervical spines including the atlas, axis, C3 and C4, as well as the mastoid process. It inserts inferiorly on the superior angle of the medial scapula [2]. Mori termed the LSM as having a dorsal and ventral fasciculus [11]. The variation seen in our report is similar to his description of the first subtype of dorsal fasciculi, in which the accessory attachment is inserted into the cervical vertebrae and the inferior attachment is to an unidentifiable assortment of vertebrae (in this case, superomedial border of the scapula) [6], [11]. Reportedly, in a recent study regarding the morphometric properties of back muscles, the authors noted that a finding of a double headed LSM with a superomedial scapular border attachment indicating no literature describing our exact variation [12]. This is rarely seen and as with the above examples of variations, it may remain unnoticed or contribute to pathological conditions.

There are suppositions that the extra belly could possibly increase stabilization and control of the scapula [1]. In a study of the muscle's action during shoulder movement, electromyography results reveal a concentric contraction during active shoulder abduction of the first $90^{\circ}$ and eccentric during the latter half [13]. With this, further research would be needed to determine whether accessory attachments can add or reinforce functions of the LSM.

\section{Clinical correlations}

It is important for physicians to note variations in muscular morphology to provide patients with proper treatment. Behrsin and Maguire determined that the LSM is implicated in referred shoulder pain while exerting force during shoulder abduction based on scapular position [13]. In the presence of a joint anomaly, this force acts specifically on the cervical spine through the cervical attachment causing tissue distortion and stress. This is contraindicated in a study by Navarro-Ledesma et al., where the LSM did not show a difference between symptomatic and asymptomatic groups in subacromial pain syndrome, but scapular positions were not noted in this study [14].

The levator scapula is anatomically important in maintaining the alignment of the neck and back; thus, the balance may be disrupted when anomalies are present in this muscle [3]. Chronic postural imbalance potentially manifests as shoulder pain or neck pain as the cervical vertebrae alignment is partially dependent on the LSM [3]. As previously mentioned, this cadaver had a severe case of thoracic kyphosis; a symptom often seen as a result of bad posture (Figure 3).

The LSM is also involved in cervical dystonia, a group of neck muscle disorders that include spasmodic torticollis, in which the head is tilted with the ear down and chin up [4]. Although the main muscle target in torticollis is thought to be the sternocleidomastoid muscle, recently, abnormalities of the LSM have been heavily implicated in this disorder [15]. Erro et al. were able to improve posture of torticollis patients significantly using electromyography to guide the administration of botulinum toxin injections into the LSM which improved the posture significantly [15].

\section{Conclusion}

An accessory belly of the LSM is significant for both its possible embryological derivatives and clinical relevance in regard to thoracic and other postural curvatures. With further research, a variation such as this can be helpful in pain management along as altering surgical procedures of the posterior cervical neck. Considering the potential solutions in knowledge of the levator scapula variations, it is scientifically valuable to continually report anomalies found related to the LSM. 


\section{References}

1. Au J, Webb A, Buirski G, Smith P, Pickering M, Perriman D. Anatomic variations of levator scapulae in a normal cohort: An MRI study. Surg Radiol Anat. 2016;39(3):337-43. https://doi. org/10.1007/s00276-016-1727-5

PMid:27515303

2. Paine $R$, Voight $M$. The role of the scapula. Int $\mathrm{J}$ Sports Phys Ther. 2013;8(5):617-29.

$$
\text { PMid:24175141 }
$$

3. Smit J, Todd M. A cadaveric study: The morphometric differences in the levator scapulae muscle. Anat J Afr. 2019;8(2):1504-14.

4. Chotai $P$, Loukas M, Tubbs R. Unusual origin of the levator scapulae muscle from mastoid process. Surg Radiol Anat. 2015;37(10):1277-81. https://doi.org/10.1007/ s00276-015-1508-6

PMid:26074045

5. Loukas M, Louis R, Merbs W. A case of atypical insertion of the levator scapulae. Folia Morphol (Warsz). 2006;65(3):232-5 PMid:16988922

6. Bakkum B, Miller N. Back Muscles. Bergman's Comprehensive Encyclopedia of Human Anatomic Variation Hoboken: Wiley-Blackwell; 2016. p. 262-88. https://doi. org/10.1002/9781118430309.ch30

7. Lima GV, Cabral R, Andrade D, Lacerda N, Araújo V, Masuko T. An unusual anatomical variation of the levator scapulae muscle. Int J Morphol. 2012;30(3):866-9. https://doi.org/10.4067/ s0717-95022012000300016

8. Aulehla A, Pourquie $O$. Signaling Gradients during paraxial mesoderm development. Cold Spring Harb Perspect Biol. 2009;2(2):a000869. https://doi.org/10.1101/cshperspect. a000869

PMid:20182616
9. Bishop K, Varacallo M. Anatomy, Shoulder and Upper Limb, Dorsal Scapular Nerve. Treasure Island (FL): Stat Pearls Publishing; 2020

10. Pu Q, Huang R, Brand-Saberi B. Development of the shoulder girdle musculature. Dev Dyn. 2016;245(3):342-50. https://doi. org/10.1002/dvdy.24378

PMid:26676088

11. Mori M. Statistics on the musculature of the Japanese. Okajimas Folia Anat Jpn. 1964;40(3):195-300. https://doi.org/10.2535/ ofaj1936.40.3_195

PMid: 14213705

12. Beger $O$, Dinç $U$, Beger $B$, Uzmansel $D$, Kurtoğlu $Z$. Morphometric properties of the levator scapulae, rhomboid major, and rhomboid minor in human fetuses. Surg Radiol Anat. 2018;40(4):449-55. https://doi.org/10.1007/s00276-018-2002-8 PMid:29541801

13. Behrsin J, Maguire K. Levator scapulae action during shoulder movement: A possible mechanism for shoulder pain of cervical origin. Aust J Physiother. 1986;32(2):101-6. https://doi. org/10.1016/s0004-9514(14)60646-2

PMid:25026444

14. Navarro-Ledesma S, Fernandez-Sanchez M, Struyf $F$, Martinez-Calderon J, Miguel Morales-Asencio $J$, et al. Differences in scapular upward rotation, pectoralis minor and levator scapulae muscle length between the symptomatic, the contralateral asymptomatic shoulder and control subjects: A cross-sectional study in a Spanish primary care setting. BMJ Open. 2019;9(6):e023020. https://doi.org/10.1136/ bmjopen-2018-023020

PMid:31196895

15. Erro R, Bhatia K, Catania S, Shields K, Cordivari C. When the levator scapulae becomes a rotator capitis: Implications for cervical dystonia. Parkinsonism Relat Disord. 2013;19(7):7056. https://doi.org/10.1016/j.parkreldis.2013.03.012 PMid:23611686 